Schriftbilder und Bilderschriften 
Helga Lutz

\section{Schriftbilder \\ und \\ Bilderschriften}

Zum Verhältnis von Text, Zeichnung und Schrift bei Unica Zürn

Verlag J.B. Metzler

Stuttgart $\cdot$ Weimar 
Das Buch basiert auf der Dissertationsschrift »Schriftbilder und Bilderschriften.

Zum Spiel mit den Grenzen von Text, Zeichnung und Schrift in den Arbeiten Unica Zürns«, eine Untersuchung die 1999 von der Humboldt Universität zu Berlin angenommen wurde.

Die Arbeit wurde durch ein Nafög Stipendium sowie durch ein Abschlußstipendium des Förderprogramms Frauenforschung des Senats Berlin unterstützt.

Bibliografische Information Der Deutschen Bibliothek

Die Deutsche Bibliothek verzeichnet diese Publikation in der Deutschen

Nationalbibliografie; detaillierte bibliografische Daten sind im Internet über $<$ http.//dnd.ddb.de> abrufbar

$$
\begin{gathered}
\text { ISBN 978-3-476-45322-8 } \\
\text { ISBN 978-3-476-o2939-3 (eBook) } \\
\text { DOI 10.1007/978-3-476-02939-3 }
\end{gathered}
$$

Dieses Werk einschließlich aller seiner Teile ist urheberrechtlich geschützt. Jede Verwertung außerhalb der engen Grenzen des Urheberrechtsgesetzes ist ohne Zustimmung des Verlages unzulässig und strafbar. Das gilt insbesondere für Vervielfältigungen, Übersetzungen, Mikroverfilmungen und die Einspeicherung und Verarbeitung in elektronischen Systemen.

M\&P Schriftenreihe für Wissenschaft und Forschung

(C) 2003 Springer-Verlag GmbH Deutschland Ursprünglich erschienen bei J.B. Metzlersche Verlagsbuchhandlung und Carl Ernst Poeschel Verlag GmbH in Stuttgart 2003

www.metzlerverlag.de info@metzlerverlag.de 


\section{Inhalt}

I. Einleitung 7

2. Das Weben der Erinnerungen 13

3. Topoi der Rezeptionsgeschichte 2 I

3.I. Modell Nr. I: "Das Ineinander von Kunst und Leben" oder "Die Gescheiterte" 2 I

3.2. Modell Nr. 2: "Die Wahnsinnige" 28

3.3. Modell Nr. 3: Das Verhältnis Zürn - Bellmer 38

4. Frühe Experimente auf dem Feld der Sprache 49

4.I. Anagrammatische Textpraxis versus historische Rekonstruktion 49

4.2. Spuren des "Berliner Surrealismus « in den Arbeiten Unica Zürns $\quad 56$

5. Die Zeichnungen Zürns im Kontext der Pariser Kunstszene der fünfziger Jahre 69

5.I. Zürn und der späte Surrealismus 69

5.2. Der "geduldige Automatismus « der Zeichnungen Zürns 75

5.3. Zürn und Wols. Wegbereiter des Informel 84

6. Zur Frage der Diskursivierung von struktureller Offenheit 95

7. Bild- und Textstrategien Zürns an ausgewählten Beispielen I09

7.I. Verweisstrukturen am Beispiel der "Hexentexte" Io9

7.2. Textkörper und Körperschrift. Ein Ölbild von $1956 \quad 125$

7.3. Mediale Nahtstellen und Sprachspiele im

"Haus der Krankheiten" $\quad$ I36

7.4. Anagramme in Text, Zeichnung und Schrift I53

8. Nachwort 169

9. Literaturverzeichnis 173 